Chronic Obstructive Pulmonary Diseases: Journal of the COPD Foundation

\author{
Original Research
}

\title{
Effect of Lung Volume Reduction Surgery on Respiratory Muscle Strength in Advanced Emphysema
}

Rachel N. Criner, MD ${ }^{1}$ Daohai Yu, $\mathrm{PhD}^{2}$ Michael R. Jacobs, PharmD ${ }^{3}$ Gerard J. Criner, $\mathrm{MD}^{3}$

\section{Abstract}

Background: Long-term effects of lung volume reduction surgery (LVRS) on respiratory muscle strength and effects of age, sex, and emphysema pattern on these changes are unknown. Therefore, we aimed to determine the long-term effect of LVRS on respiratory muscle strength changes in severe emphysema.

Methods: The National Emphysema Treatment Trial was a prospective controlled multicentered trial, comparing LVRS to optimal medical treatment on survival and maximal exercise capacity. We examined percentage change in maximum inspiratory pressure (MIP) from baseline to 36 months follow-up to determine impact of LVRS as well as age, sex, emphysema pattern and exercise capacity on changes in MIP compared to medical treatment. Results: LVRS individuals had significantly greater increases in MIP from baseline compared to medical individuals at all follow-ups (LVRS $19.8 \pm 42.3 \%$, medical $3.2 \pm 29.3 \%, p<0.0001,12$ months). The LVRS group had significant decreases in total lung capacity (TLC), residual volume (RV), functional residual capacity (FRC) and RV/TLC compared to the medical arm at all follow-up periods. Males and individuals 65-70 years of age had significantly greater increases in MIP following LVRS compared to the medical arm at all follow-ups; this same relationship was seen at up to 24 months for low exercise capacity, upper lobe predominant emphysema. Conclusions: LVRS significantly increases inspiratory muscle strength up to 3 years post-operatively, with male sex, age 65-70 years and low exercise capacity, upper lobe predominant emphysema especially associated with increased MIP. Inspiratory muscle strength increases were associated with decreases in non-invasive markers of dynamic hyperinflation, suggesting that LVRS allows inspiratory muscles to return to their optimal lengthtension relationship.

\begin{abstract}
Abbreviations: lung volume reduction surgery, LVRS; maximum inspiratory pressure, MIP; total lung capacity, TLC; residual volume, RV; functional residual capacity, FRC; National Emphysema Treatment Trial, NETT; respiratory muscle strength, RMS; body mass index, BMI; forced expiratory volume in 1 second, $\mathbf{F E V}_{\mathbf{1}}$; confidence interval, CI

Funding Support: Supported by contracts with the National Heart, Lung, and Blood Institute (N01HR76101, N01HR76102, N01HR76103, N01HR76104, N01HR76105, N01HR76106, N01HR76107, N01HR76108, N01HR76109, N01HR76110, N01HR76111, N01HR76112, N01HR76113, N01HR76114, N01HR76115, N01HR76116, N01HR76118, and N01HR76119), the Centers for Medicare and Medicaid Services, and the Agency for Healthcare Research and Quality.

Date of Acceptance: July 16, 2018

Citation: Criner RN, Yu D, Jacobs MR, Criner GJ. Effect of lung volume reduction surgery on respiratory muscle strength in advanced emphysema. Chronic Obstr Pulm Dis. 2019;6(1):In press. doi: https://doi.org/10.15326/jcopdf.6.1.2018.0188
\end{abstract}

1 Department of Internal Medicine, University of Michigan, Ann Arbor

2 Department of Clinical Sciences, Lewis Katz School of Medicine, Temple University, Philadelphia, Pennsylvania

\section{Keywords:}

emphysema; dynamic hyperinflation; lung volume reduction surgery; respiratory muscle strength; mean inspiratory pressure; sex; age; exercise capacity

3 Department of Thoracic Medicine and Surgery, Lewis Katz School of Medicine, Temple University, Philadelphia, Pennsylvania 


\section{Address correspondence to:}

Rachel N. Criner, MD

Department of Internal Medicine

University of Michigan Health Systems

UH Internal Medicine - Core 3116 TC

1500 E. Medical Center Drive

Ann Arbor, MI 48109

rcriner@med.umich.edu

734-936-4385

\section{This article contains an online supplement.}

\section{Introduction}

Emphysema is a progressive disease characterized by small airway destruction and reduced lung elastic recoil that precipitates air trapping during expiration. ${ }^{1,2}$ This results in hyperinflation, which is characterized by an increase in functional residual capacity and a concomitant decrease in inspiratory capacity. The overall increase in end-expiratory lung volumes causes contractile dysfunction of the inspiratory muscles, i.e., the diaphragm and external intercostal and accessory muscles, preventing adequate inspiratory muscle force generation. ${ }^{3}$

Structurally, hyperinflation flattens the diaphragm, leading to passive shortening of the diaphragm; this distorts the optimal length-tension relationship for skeletal muscle contraction and leads to weakened diaphragm contraction. ${ }^{3-8}$ Also, hyperinflation causes less rib cage area to be exposed to positive abdominal pressure generated by diaphragm contraction; this decrease in the zone of apposition prevents adequate rib cage expansion with inspiration, thus further impairing negative intrathoracic pressure generation. ${ }^{4,7}$ Biochemically, hyperinflation leads to upregulation of nuclear factor kappa beta, which leads to decreased MyoD expression, resulting in dysregulation of muscle differentiation as well as diaphragm protein degradation via the ubiquitinproteasome pathway. ${ }^{9,10}$ When faced with increased ventilatory workloads, such as during exercise, hyperinflation and its consequences causes severely emphysematous patients to experience increased respiratory muscle fatigue and increased energy expenditure. ${ }^{11}$ An increase in respiratory muscle force generation is an important goal because hypercapneic respiratory failure secondary to inspiratory muscle fatigue is an important contributor to mortality in chronic obstructive pulmonary disease. ${ }^{9,12}$
Several studies have found lung volume reduction surgery (LVRS) to decrease residual volume and inspiratory muscle workload and to increase diaphragm length, the zone of apposition, and elastic recoil, resulting in improved inspiratory muscle mechanics; reduction in hyperinflation increases diaphragm strength, exercise capacity, maximal oxygen consumption, maximal minute ventilation, and maximum voluntary ventilation. ${ }^{12-15}$ These changes improve respiratory muscle mechanics, which increases exercise tolerance and decreases dyspnea to a greater degree than medical therapy. ${ }^{15}$ However, these studies are small in number, rarely controlled, and only report results of no more than 6 months postLVRS.

We therefore conducted a retrospective analysis using prospectively collected data from the National Emphysema Treatment Trial(NETT), a large population of 1218 patients with severe bilateral emphysema who were followed over a 5 -year period to determine the short and long-term effects of LVRS compared to optimal medical management on respiratory muscle strength (RMS). ${ }^{16,17}$ We also analyzed if age, sex, body mass index (BMI), distribution of emphysema and exercise capacity affected changes in respiratory muscle strength after LVRS compared to medical therapy.

\section{Methods}

\section{Study Design}

The National Emphysema Treatment Trial was a prospective multicenter randomized controlled clinical trial that enrolled 1218 individuals with severe emphysema between 1998-2002. The main objective was to compare the effect of optimal medical treatment plus LVRS versus optimal medical treatment alone on the co-primary outcomes of survival and maximal exercise capacity. Methods, design, and outcome for NETT were published previously. ${ }^{16,17}$

A secondary outcome of NETT was RMS evaluation via maximum static inspiratory pressures (MIP) measurements at baseline, 6 months after randomization, and then yearly for 5 years after randomization. Outcome measurements were analyzed up to 3 years post-randomization. NETT represents the largest dataset of longitudinal measurements of global RMS ever obtained in patients with severe 
emphysema.

\section{Study Participants}

Enrollment criteria included bilateral emphysema on high-resolution computerized tomography scan and pre-rehab forced expiratory volume in 1 second (FEV $)_{1}$ $\leq 45 \%$ predicted. Before randomization, participants underwent comprehensive medical evaluations and then participated in 16 to 20 pulmonary rehabilitation sessions over 6 to 10 weeks. Baseline measurements were obtained after rehabilitation but before randomization. Participants were then randomized to either LVRS with medical treatment or to medical treatment alone. The institutional review board for human studies approved the protocol, and all participants provided written consent.

\section{Pulmonary Function Measurements}

The forces generated by respiratory muscles, including the diaphragm and external intercostal and accessory muscles, were determined by MIP, which were measured at the airway opening with a flanged mouthpiece during a voluntary contraction against an occluded airway, using the Black and Hyatt techniques. ${ }^{18}$ MIP was measured at residual volume. Participants generated MIP 3-10 times, until 3 measurements were within $5 \mathrm{~cm} \mathrm{H}_{2} \mathrm{O}$ of the maximum value. The average of these 3 measurements was reported in our analyses. Total lung capacity (TLC), residual volume (RV), functional residual capacity (FRC) and ratio of residual volume to total lung capacity (RV/TLC) were measured using plethysmography. TLC is the volume of air in the lungs at the end of maximal inspiration, and $R V$ is the volume of air in the lungs after maximal exhalation. FRC is the volume of air remaining in the lungs at the end of passive expiration, and RV/TLC was obtained by dividing the volume of air in the lungs after maximal exhalation by the volume of air in the lungs at the end of maximal inspiration.

\section{Statistical Analysis}

Data are displayed as mean $\pm S D$ for continuous variables and count and percentage for categorical variables. MIP percentage changes from baseline to 6 through 36 months follow-up were analyzed and further compared between treatment arms at each follow-up interval using Wilcoxon rank-sum tests. These data analyses were repeated to determine impacts of age, sex, BMI, risk stratification, emphysema pattern, and exercise capacity on MIP percentage changes between treatment arms up to 3 years post-operatively; unadjusted $p$-values comparing treatment groups were obtained from this approach. Additionally, absolute changes in TLC, RV, FRC and RV/TLC from baseline to 6 through 36 months follow-up were compared between treatment arms at each follow-up interval using Wilcoxon rank-sum tests.

Participants were deemed high risk if $\mathrm{FEV}_{1} \leq 20 \%$ of predicted value and either homogenous emphysema or a carbon monoxide diffusing capacity that was $20 \%$ or less of predicted value at baseline; those not meeting these criteria at baseline were deemed nonhigh risk and further categorized by emphysema lobe predominance and exercise capacity. ${ }^{17}$ The NETT characterized participants as either predominantly non-upper lobe emphysema or upper lobe emphysema based on a baseline computerized tomography scan read by each center's radiologist. ${ }^{17}$ Predominantly nonupper lobe emphysema consisted of emphysematous patterns that were diffuse, predominantly lower lobe, or predominantly distributed in superior segments of lower lobes. ${ }^{17}$ Participants were categorized as either high exercise capacity if they had a maximum workload greater than $40 \%$ for their sex at baseline or low exercise capacity if their maximum workload was $40 \%$ or less; $40 \%$ or less corresponded to a maximum workload of less than 25 watts for females and less than 40 watts for males. ${ }^{17}$

Moreover, mixed-effects models were fitted to MIP change data, pooling all follow-up intervals together to adjust for various covariates, i.e., baseline MIP, follow-up time, sex, age, BMI, emphysema pattern, exercise capacity, and risk categorization, while also accounting for the correlation among the observations from the same participants over time when comparing treatments. Interaction terms between independent variables were also considered in the model. Adjusted $p$-values comparing treatment groups were derived from such models with adjustments for the aforementioned covariates at visit times 6 through 36 months. Data transformation (e.g., log or square-root) was considered when a variable on the original scale was not approximately normally distributed. $P$-values $<0.05$ were considered statistically significant. Statistical analyses were performed using SAS V9.3 software (SAS Institute Inc., Cary, North Carlolina). 


\section{Results}

From January 1998 to July 2002, NETT enrolled 1218 patients with severe emphysema and recent completion of 6-10 weeks of pulmonary rehabilitation. A total of 610 individuals were randomized to medical treatment while 608 individuals were randomized to LVRS; see Table 1 for baseline demographics. Of the LVRS group, there were 603 MIP measurements with mean MIP $62.1 \pm 22.7 \mathrm{~cm} \mathrm{H} \mathrm{H}_{2} \mathrm{O}$. For the medical group, there were $602 \mathrm{MIP}$ measurements with mean baseline MIP $62.0 \pm 22.3 \mathrm{~cm} \mathrm{H}$. . Baseline MIPs for various characteristics, such as sex, age, BMI, risk stratification, and lobe predominance and exercise capacity, were similar between the groups (Table 2).

At all follow-up periods, the LVRS group had a significantly greater increase in MIP from baseline, when compared to the medical arm (19.8 $\pm 42.3 \%$ increase in LVRS versus $3.2 \pm 29.3 \%$ increase in medical, $p<0.0001$ at 12 months; Table 3$)$. The LVRS group also had significant decreases in TLC, RV, FRC and RV/TLC, when compared to the medical arm at all follow-up periods (For TLC, $0.66 \pm 0.8$ decrease in LVRS versus $0.09 \pm 0.7$ decrease in medical, $p<0.0001$ at 12 months; for RV, $0.83 \pm 1.0$ decrease in LVRS versus $0.00 \pm 0.8$ increase in medical, $p<0.0001$ at 12 months; for FRC, $0.77 \pm 0.9$ decrease in LVRS versus $0.03 \pm 0.8$ decrease in medical, $p<0.0001$ at 12 months; for RV/TLC, $0.06 \pm 0.1$ decrease in LVRS versus. $0.01 \pm$ 0.1 increase in medical, $p<0.0001$; Table 3).

Males in the LVRS arm also had significantly greater increases in MIP, compared to those in the medical arm, at all follow-up periods (increase of $19.5 \pm 3.5 \%$ at 12 months, $p<0.0001,95 \%$ confidence interval [CI] [12.726.3]; Table 4). Females in the LVRS group also had greater increases in MIP from baseline when compared to females in the medical arm but significance was lost at 24 and 36 months (increase of $13.6 \pm 4.2 \%$ at 12 months, $p=0.0017,95 \%$ CI [5.0-21.6]).

For all age groups, LVRS led to greater increases in MIP from baseline when compared to optimal medical therapy. This trend was significant at all follow-up periods for those 65- to 70-years-old (increase of 14.9 $\pm 4.3 \%$ at 12 months, $p=0.0005$, 95\% CI [6.5-23.2]; Table 5). This trend was only significant at up to 24 months for those less than 60-years-old and at up to 12 months for those 60- to 65-years-old (increase of 14.4 $\pm 3.6 \%, p<0.0001,95 \%$ CI [7.3-21.5] and increase of $19.9 \pm 5.9 \%, p=0.0008,95 \%$ CI [8.3-31.5], respectively).

\section{Table 1. Baseline Demographics ${ }^{a, b}$}

\begin{tabular}{|c|c|c|}
\hline Demographics & $\begin{array}{c}\text { LVRS } \\
(n=603)\end{array}$ & $\begin{array}{c}\text { Medical } \\
(n=602)\end{array}$ \\
\hline \multicolumn{3}{|l|}{ Age at Entry-years } \\
\hline Median & 68.0 & 68.0 \\
\hline Mean \pm SD & $67.1 \pm 5.9$ & $67.3 \pm 5.9$ \\
\hline BMI- $-\mathrm{kg} / \mathrm{m}^{2}(\text { mean } \pm \mathrm{SD})^{\mathrm{c}}$ & $24.5 \pm 3.8$ & $24.7 \pm 3.8$ \\
\hline \multicolumn{3}{|l|}{ Sex } \\
\hline Female & $251(42 \%)$ & $215(36 \%)$ \\
\hline Male & $352(58 \%)$ & 387 (64\%) \\
\hline \multicolumn{3}{|l|}{ Age } \\
\hline Less than 60-years-old & $287(48 \%)$ & $263(44 \%)$ \\
\hline 60- to less than 65-years-old & $101(17 \%)$ & $104(17 \%)$ \\
\hline 65- to less than 70-years-old & $195(32 \%)$ & $219(36 \%)$ \\
\hline 70-years-old or greater & $20 \quad(3 \%)$ & $16(3 \%)$ \\
\hline \multicolumn{3}{|l|}{$\mathbf{B M I}^{\mathbf{c}}$} \\
\hline Less than $25 \mathrm{~kg} / \mathrm{m}^{2}$ & $326(57 \%)$ & $308(52 \%)$ \\
\hline $25 \mathrm{~kg} / \mathrm{m}^{2}$ or greater & $250(43 \%)$ & $281(48 \%)$ \\
\hline \multicolumn{3}{|l|}{ Risk Stratification $^{\mathrm{d}}$} \\
\hline High Risk & $69(11 \%)$ & $69(11 \%)$ \\
\hline Non-high Risk & $534(89 \%)$ & $533(89 \%)$ \\
\hline \multicolumn{3}{|l|}{ Exercise Capacity $^{\mathbf{e}}$} \\
\hline High & $331(62 \%)$ & $321(60 \%)$ \\
\hline Low & $203(38 \%)$ & $211(40 \%)$ \\
\hline \multicolumn{3}{|c|}{ Emphysema Lobe Distribution ${ }^{\mathrm{e}}$} \\
\hline Upper Lobe & $368(39 \%)$ & $360(67 \%)$ \\
\hline Non-upper Lobe & $166(31 \%)$ & $173(33 \%)$ \\
\hline
\end{tabular}

${ }^{a}$ Values are number of participants $(n)$ unless otherwise indicated.

${ }^{b}$ Baseline demographics were collected after pulmonary

rehabilitation but before randomization.

${ }^{\mathrm{C}}$ Excludes 27 participants with missing BMI in the LVRS group and 13 participants with missing BMI in the medical therapy group.

${ }^{\mathrm{d}}$ The National Emphysema Treatment Trial defined high risk and

non-high risk groups. ${ }^{17}$ High risk patients were those with $\mathrm{FEV}_{1} \leq$ $20 \%$ of predicted value and either homogenous emphysema or a carbon monoxide diffusing capacity that was $20 \%$ or less of predicted value; patients were considered non-high risk if they did not meet the above criteria.

e The National Emphysema Treatment Trial categorized participants as high exercise capacity if they had a maximum workload greater than $40 \%$ for their sex at baseline or low exercise capacity if their maximum workload was $40 \%$ or less. ${ }^{17}$ Forty percent or less corresponded to a maximum workload of less than 25 watts for females and less than 40 watts for males. The National Emphysema Treatment Trial defined participants as either predominantly nonupper lobe emphysema or upper lobe emphysema based on a baseline computerized tomography scan read by each center's radiologist. ${ }^{17}$ Predominantly non-upper lobe emphysema consisted of emphysematous patterns that were diffuse, predominantly lower lobe, or predominantly distributed in superior segments of lower lobes. High risk individuals, as defined by the National Emphysema Treatment Trial, were excluded. ${ }^{17}$

LVRS=lung volume reduction surgery; $\mathrm{SD}=$ standard deviation, $\mathrm{BMI}=$ body mass index, upper lobe=upper lobe predominant emphysema; non-upper=non-upper lobe predominant emphysema 


\section{Table 2. Baseline Maximum Inspiratory Pressure Measurements ${ }^{\mathrm{a}, \mathrm{b}}$}

\begin{tabular}{|c|c|c|}
\hline Characteristics & LVRS & Medical \\
\hline Mean MIP & $62.1 \pm 22.7(n=603)$ & $62.0 \pm 22.3(n=602)$ \\
\hline \multicolumn{3}{|l|}{ Sex } \\
\hline Male & $67.5 \pm 22.6(n=352)$ & $67.7 \pm 22.2(n=387)$ \\
\hline Female & $53.3 \pm 19.8(n=251)$ & $51.7 \pm 18.5(n=215)$ \\
\hline \multicolumn{3}{|l|}{ Age } \\
\hline Less than 60-years-old & $60.5 \pm 22.8(n=287)$ & $61.2 \pm 21.5(n=263)$ \\
\hline 60- to less than 65-years-old & $63.2 \pm 22.2(n=101)$ & $64.7 \pm 24.4(n=104)$ \\
\hline 65- to less than 70-years-old & $63.9 \pm 23.2(n=195)$ & $62.1 \pm 22.6(n=219)$ \\
\hline 70-years-old or greater & $61.9 \pm 19.3(n=20)$ & $56.8 \pm 17.1(n=16)$ \\
\hline \multicolumn{3}{|l|}{ Body Mass Index ${ }^{c}$} \\
\hline Less than $25 \mathrm{~kg} / \mathrm{m}^{2}$ & $59.1 \pm 21.1(n=326)$ & $59.4 \pm 22.0(n=308)$ \\
\hline $25 \mathrm{~kg} / \mathrm{m}^{2}$ or greater & $64.9 \pm 23.7(n=250)$ & $64.5 \pm 22.5(n=281)$ \\
\hline \multicolumn{3}{|l|}{ Risk Stratification $^{\mathrm{d}}$} \\
\hline High Risk & $62.1 \pm 48.0(n=69)$ & $59.2 \pm 22.7(n=69)$ \\
\hline Non-high Risk & $62.1 \pm 23.0(n=534)$ & $62.4 \pm 22.3(n=533)$ \\
\hline \multicolumn{3}{|c|}{ Lobe Predominance and Exercise Capacity ${ }^{e}$} \\
\hline Upper Lobe, High Capacity & $65.3 \pm 21.8(n=204)$ & $64.4 \pm 21.7(n=210)$ \\
\hline Upper Lobe, Low Capacity & $56.1 \pm 20.2(n=138)$ & $57.3 \pm 23.0(n=149)$ \\
\hline Non-upper, High Capacity & $67.7 \pm 25.0(n=109)$ & $68.3 \pm 20.0(n=110)$ \\
\hline Non-upper, Low Capacity & $56.7 \pm 24.3(n=82)$ & $57.5 \pm 23.0(n=64)$ \\
\hline
\end{tabular}

${ }^{\mathrm{a}}$ Values are mean $\pm \mathrm{SD}$ with the units $\mathrm{cm} \mathrm{H}_{2} \mathrm{O}$, unless otherwise indicated.

${ }^{\mathrm{b}}$ Baseline maximum inspiratory pressure measurements were collected after pulmonary

rehabilitation but before randomization.

${ }^{c}$ Excludes 27 participants with missing BMI in the LVRS group and 13 participants with missing BMI in the medical therapy group.

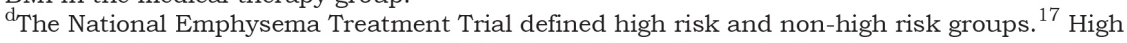
risk patients were those with $\mathrm{FEV}_{1} \leq 20 \%$ of predicted value and either homogenous emphysema or a carbon monoxide diffusing capacity that was $20 \%$ or less of predicted value; patients were considered non-high risk if they did not meet the above criteria.

${ }^{\mathrm{e}}$ The National Emphysema Treatment Trial categorized participants as high exercise capacity if they had a maximum workload greater than $40 \%$ for their sex at baseline or low exercise capacity if their maximum workload was $40 \%$ or less. ${ }^{17}$ Forty percent or less corresponded to a maximum workload of less than 25 watts for females and less than 40 watts for males. The National Emphysema Treatment Trial defined participants as either predominantly non-upper lobe emphysema or upper lobe emphysema based on a baseline computerized tomography scan read by each center's radiologist. ${ }^{17}$ Predominantly non-upper lobe emphysema consisted of emphysematous patterns that were diffuse, predominantly lower lobe, or predominantly distributed in superior segments of lower lobes. High risk participants, as defined by the National Emphysema Treatment Trial, were excluded. $^{17}$

LVRS=lung volume reduction surgery; $\mathrm{MIP}=$ maximum inspiratory pressure; upper lobe=upper lobe predominant emphysema; non-upper=non-upper lobe predominant emphysema; high capacity=high exercise capacity; low capacity=low exercise capacity

Analysis was not performed on participants older than 70-years-old because $n$ was less than 15 at all followup periods for both treatment arms.

LVRS participants with upper lobe predominant emphysema and low exercise capacity had the greatest increase in MIP post procedure but was only significant at up to 24 months (increase of $22.0 \pm 5.1 \%, p<0.0001$, 95\% CI [11.9-32.1]). Non-upper lobe emphysematous participants with low exercise capacity did not have a consistently significant greater increase in MIP in the LVRS arm when compared to the medical arm.
Regardless of emphysema distribution, LVRS participants with high exercise capacity had significantly greater MIP increases than those in the medical arm at all follow-up periods (increase of $11.2 \pm 5.5 \%, p=0.0426,95 \%$ CI [0.422.1] in non-upper lobe emphysema and increase of $18.9 \pm 4.0 \%, p<0.0001$, 95\% CI [11.0-26.7] in upper lobe predominant emphysema; Table 6). High risk participants in the LVRS arm had a significantly greater increase in MIP compared to the medical arm but only at up to 12 months follow-up (increase of $22.7 \pm 7.8 \%, p=0.0035$, 95\% CI [7.5-38.0]).

BMI did not affect change in MIP for either treatment arm at any follow-up period (Tables S3 and S4 in online data supplement).

\section{Discussion}

Our data confirms findings of previous studies that found LVRS to increase inspiratory muscle strength, however with smaller study populations and follow-up durations. Martinez and colleagues found MIP to significantly increase by $22 \%$ at 3 months postLVRS in a study of 17 patients with severe emphysema and hyperinflation with debilitating symptoms. ${ }^{14}$ Criner and colleagues found in 20 patients with severe, non-bullous and diffuse emphysema who underwent LVRS that MIP significantly increased from baseline by $48 \%$ and was significantly greater than medical management at 3 months postoperatively. ${ }^{11}$ Other indicators of inspiratory muscle strength, including transdiaphragmatic pressure during maximum sniff, electrophrenic diaphragm twitch stimulation, and combined expulsive-Mueller maneuver, were also greater at 3 months post-surgery. Teschler and colleagues also found MIP to significantly increase by $52 \%$ at 1 -month post-LVRS in a study of 17 patients with severe emphysema and dyspnea on minimal exertion. ${ }^{19}$ 


\section{Table 3. Differences in Various Pulmonary Function Measurements from Baseline to Visit Time ${ }^{a, b}$}

\begin{tabular}{|c|c|c|c|c|c|}
\hline \multirow[t]{2}{*}{ Visit (Months) } & \multicolumn{2}{|r|}{ LVRS } & \multicolumn{2}{|c|}{ Medical } & \multirow[t]{2}{*}{$p$-value ${ }^{c}$} \\
\hline & $n$ & Mean \pm SD & $n$ & Mean \pm SD & \\
\hline \multicolumn{6}{|l|}{6} \\
\hline MIP & 489 & $16.8 \pm 35.7$ & 438 & $0.8 \pm 29.0$ & $<0.0001$ \\
\hline TLC & 494 & $-0.59 \pm 1.0$ & 441 & $-0.06 \pm 0.6$ & $<0.0001$ \\
\hline RV & 494 & $-0.76 \pm 1.2$ & 441 & $0.01 \pm 0.7$ & $<0.0001$ \\
\hline FRC & 494 & $-0.72 \pm 1.1$ & 442 & $-0.02 \pm 0.7$ & $<0.0001$ \\
\hline RV/TLC & 494 & $-0.06 \pm 0.1$ & 441 & $0.01 \pm 0.1$ & $<0.0001$ \\
\hline \multicolumn{6}{|l|}{12} \\
\hline MIP & 420 & $19.8 \pm 42.3$ & 362 & $3.2 \pm 29.3$ & $<0.0001$ \\
\hline TLC & 422 & $-0.66 \pm 0.8$ & 363 & $-0.09 \pm 0.7$ & $<0.0001$ \\
\hline RV & 422 & $-0.83 \pm 1.0$ & 363 & $0.00 \pm 0.8$ & $<0.0001$ \\
\hline FRC & 422 & $-0.77 \pm 0.9$ & 364 & $-0.03 \pm 0.8$ & $<0.0001$ \\
\hline RV/TLC & 422 & $-0.06 \pm 0.1$ & 363 & $0.01 \pm 0.1$ & $<0.0001$ \\
\hline \multicolumn{6}{|l|}{24} \\
\hline MIP & 351 & $16.6 \pm 38.5$ & 286 & $1.2 \pm 31.0$ & $<0.0001$ \\
\hline TLC & 355 & $-0.62 \pm 0.8$ & 290 & $-0.18 \pm 0.7$ & $<0.0001$ \\
\hline RV & 355 & $-0.72 \pm 1.1$ & 290 & $-0.04 \pm 0.9$ & $<0.0001$ \\
\hline FRC & 355 & $-0.67 \pm 1.0$ & 290 & $-0.11 \pm 0.9$ & $<0.0001$ \\
\hline RV/TLC & 355 & $-0.05 \pm 0.1$ & 290 & $0.01 \pm 0.1$ & $<0.0001$ \\
\hline \multicolumn{6}{|l|}{36} \\
\hline MIP & 220 & $13.6 \pm 36.8$ & 167 & $1.1 \pm 28.6$ & 0.0004 \\
\hline TLC & 221 & $-0.59 \pm 0.9$ & 170 & $-0.23 \pm 0.8$ & $<0.0001$ \\
\hline RV & 221 & $-0.63 \pm 1.0$ & 170 & $-0.01 \pm 0.9$ & $<0.0001$ \\
\hline FRC & 221 & $-0.61 \pm 1.0$ & 170 & $-0.10 \pm 0.8$ & $<0.0001$ \\
\hline RV/TLC & 221 & $-0.04 \pm 0.1$ & 170 & $0.02 \pm 0.1$ & $<0.0001$ \\
\hline
\end{tabular}

${ }^{\mathrm{a}} \mathrm{Data}$ for MIP is presented as percentage difference while data for remaining variables are presented as absolute difference.

${ }^{b} n$ varied within treatment arms at each follow-up period as not all participants completed all pulmonary function measurements.

${ }^{c} p$-values were calculated using the Wilcoxon rank-sum test. The $p$-values were not adjusted for age, body mass index, emphysema lobe predominance, exercise capacity, and risk categorization.

LVRS=lung volume reduction surgery; $\mathrm{SD}=$ standard deviation; $\mathrm{MIP}=$ maximum inspiratory pressure; TLC=total lung capacity; $\mathrm{RV}=$ residual volume; $\mathrm{FRC}=$ functional residual capacity; $\mathrm{RV} / \mathrm{TLC}=$ ratio of residual volume to total lung capacity than their inherent strengthening.

Men who underwent LVRS, rather than women, had overall greater and longer lasting increases in MIP compared to medical only therapy. It has been previously reported that for the same age and regardless of underlying disease state, women have about $25 \%$ to $30 \%$ lower respiratory muscle strength than men. ${ }^{21-23}$ Nonetheless, as women age, they have less decline in respiratory muscle strength than men for reasons that remain unclear. $^{22}$ We may have seen greater increases in respiratory muscle strength in men because at baseline, male MIP was already greater than female MIP. Our findings suggest that LVRS may temporarily reverse the overall more rapid decline in respiratory muscle strength that has been seen in men.

Respiratory muscle strength declines with age 18,21-23; Enright et al reported a 0.8 to $2.7 \mathrm{~cm} \mathrm{H}_{2} \mathrm{O}$ per year decline in MIP in patients 65- to 85 -years-old. ${ }^{21}$ This is likely due to natural atrophy of respiratory muscles with age, which is likely exacerbated by an underlying emphysematous state. However, we found that for all age groups, LVRS significantly reversed this decline at up to 1 year post-operatively and those who were 65- to less than 70-years-old had sustained increase at up to 3 years post-operatively. The significant improvement in respiratory muscle
Lammi et al previously found that LVRS leads to a significant reduction in dynamic hyperinflation up to 3 years post-operatively in a small subgroup of upper lobe-predominant emphysema patients enrolled in NETT. ${ }^{20}$ Importantly, our analysis further supports this prior finding by demonstrating significant reductions in TLC, RV, FRC and RV/TLC at all followup time points. We suggest that the aforementioned significant increase in MIP seen at all time points in LVRS was likely due to inspiratory muscles returning to their optimal length-tension relationship, rather strength in the older participant group further supports that LVRS alters respiratory mechanics to restore the diaphragm and zone of apposition towards normal, causing an improvement in dyspnea, minute ventilation and exercise capacity. ${ }^{11,13-15}$

We found that LVRS participants with low exercise capacity and upper lobe predominant emphysema who underwent LVRS had significant increases in respiratory muscle strength at up to 24 months but those with similar exercise capacity, but nonupper lobe predominant emphysema, did not have a 


\section{Table 4. Difference in Percentage Change of Maximum Inspiratory Pressure in Lung Volume Reduction Surgery Compared to Medical Arm at Each Time Point from Baseline for Sex ${ }^{a}$}

\begin{tabular}{|c|c|c|c|c|c|}
\hline Visit & $\begin{array}{l}\text { LVRS } \\
\qquad(n)\end{array}$ & $\begin{array}{l}\text { Medical } \\
(n)\end{array}$ & $\begin{array}{l}\text { Difference } \pm \\
\text { Standard Error }\end{array}$ & $p$-value ${ }^{b}$ & $95 \% \mathrm{Cl}$ \\
\hline \multicolumn{6}{|l|}{6 Months } \\
\hline Male & 280 & 288 & $+18.5 \pm 3.0$ & $<0.0001$ & $12.5-24.5$ \\
\hline Female & 209 & 150 & $+11.7 \pm 3.8$ & 0.0020 & 4.3-19.1 \\
\hline \multicolumn{6}{|l|}{12 Months } \\
\hline Male & 238 & 231 & $+19.5 \pm 3.5$ & $<0.0001$ & $12.7-26.3$ \\
\hline Female & 182 & 131 & $+13.6 \pm 4.2$ & 0.0017 & 5.0-21.6 \\
\hline \multicolumn{6}{|l|}{24 Months } \\
\hline Male & 202 & 190 & $+15.5 \pm 3.9$ & $<0.0001$ & 8.0-23.1 \\
\hline Female & 149 & 96 & $+8.5 \pm 4.8$ & 0.0741 & 0.8-17.9 \\
\hline \multicolumn{6}{|l|}{36 Months } \\
\hline Male & 124 & 105 & $+12.5 \pm 4.5$ & 0.0057 & $3.7-21.4$ \\
\hline Female & 96 & 62 & $+9.2 \pm 5.3$ & 0.0798 & $1.1-19.5$ \\
\hline
\end{tabular}

${ }^{\mathrm{a}}$ See Table S1 in online data supplement for percentage differences in maximum inspiratory pressure from baseline to visit time for sex.

${ }^{\mathrm{b}} p$-value adjusted for age, body mass index, emphysema lobe predominance, exercise capacity, and risk categorization. Adjusted $p$-values were calculated using the mixedeffects model for percentage difference of maximum inspiratory pressure, comparing between treatment groups by sex and visit time.

LVRS=lung volume reduction surgery; $\mathrm{CI}=$ confidence interval

consistent trend in respiratory muscle strengthening at any time point. This finding agrees with prior studies that found that upper lobe emphysema leads to greater improvement in lung function after LVRS. ${ }^{24,25}$ It also correlates with the NETT trial, which found that those with low exercise capacity and upper lobe predominant emphysema had significant mortality benefit with LVRS and significant increases in exercise capacity at 24 months; they also found that those with low exercise capacity and non-upper lobe predominant emphysema had no difference in mortality and exercise capacity at 24 months. ${ }^{17}$

The NETT trial also found that those with high exercise capacity and upper lobe predominant emphysema had no mortality benefit with LVRS but did have significant improvement in exercise capacity at 24 months and those with similar exercise capacity but non-upper lobe predominant emphysema had greater risk of death with LVRS but no difference in exercise capacity at 24 months. ${ }^{17}$ Regardless of lobe predominance, we found that participants with high exercise capacity who underwent LVRS had significant increases in inspiratory muscle strength compared to the medical arm at up to 3 years follow-up. This suggests that although LVRS optimizes respiratory muscle function, this improvement in inspiratory muscle strength does not correlate to a mortality benefit. This is because low, rather than high, exercise capacity is a predictor of survival in LVRS individuals as their counterparts in the medical arm continue to functionally decline without surgery, as found by NETT. ${ }^{17}$ This finding, found in both the NETT trial and our study, is difficult to explain as it conflicts with the BODE (BMI, degree of airflow obstruction, dyspnea and exercise capacity) index, which shows that greater exercise capacity is associated with lower mortality. ${ }^{26}$

We assumed that participants with BMI $<25 \mathrm{~kg} / \mathrm{m}^{2}$ had greater respiratory muscle atrophy than those with 


\section{Table 5. Difference in Percentage Change of Maximum Inspiratory Pressure in Lung Volume Reduction Surgery Compared to Medical Arm at Each Time Point from Baseline for Age ${ }^{a}$}

\begin{tabular}{|c|c|c|c|c|c|}
\hline Visit (Months) & $\begin{array}{l}\text { LVRS } \\
\qquad(n)\end{array}$ & $\begin{array}{c}\text { Medical } \\
(n)\end{array}$ & $\begin{array}{l}\text { Difference } \pm \\
\text { Standard Error }\end{array}$ & $p$-value ${ }^{b}$ & $95 \% \mathrm{Cl}$ \\
\hline \multicolumn{6}{|l|}{6} \\
\hline Less than 60 -years-old & 243 & 196 & $+13.7 \pm 3.2$ & $<0.0001$ & $7.4-20.0$ \\
\hline 60- to $<65$-years-old & 77 & 76 & $+13.1 \pm 5.2$ & 0.0117 & $2.9-23.3$ \\
\hline 65- to 70-years-old & 155 & 157 & $+18.4 \pm 3.8$ & $<0.0001$ & $11.0-25.8$ \\
\hline \multicolumn{6}{|l|}{12} \\
\hline Less than 60-years-old & 210 & 157 & $+14.4 \pm 3.6$ & $<0.0001$ & $7.3-21.5$ \\
\hline 60- to $<65$-years-old & 67 & 62 & $+19.9 \pm 5.9$ & 0.0008 & $8.3-31.5$ \\
\hline 65- to 70-years-old & 132 & 138 & $+14.9 \pm 4.3$ & 0.0005 & $6.5-23.2$ \\
\hline \multicolumn{6}{|l|}{24} \\
\hline Less than 60-years-old & 175 & 114 & $+11.5 \pm 4.2$ & 0.0065 & $3.2-19.8$ \\
\hline 60- to $<65$-years-old & 55 & 60 & $+3.3 \pm 6.3$ & 0.6409 & $9.1-15.7$ \\
\hline 65- to 70-years-old & 113 & 106 & $+21.2 \pm 4.8$ & $<0.0001$ & 11.9-30.7 \\
\hline \multicolumn{6}{|l|}{36} \\
\hline Less than 60-years-old & 114 & 63 & $+9.1 \pm 4.8$ & 0.0588 & $0.3-18.6$ \\
\hline 60- to $<65$-years-old & 36 & 40 & $+6.2 \pm 7.0$ & 0.3783 & $7.6-20.0$ \\
\hline 65- to 70-years-old & 68 & 63 & $+17.3 \pm 5.6$ & 0.0019 & $6.4-28.2$ \\
\hline
\end{tabular}

\footnotetext{
${ }^{\mathrm{a}}$ See Table $\mathrm{S} 2$ in online data supplement for percentage differences in maximum inspiratory pressure from baseline to visit time for sex. ${ }^{b} p$-value adjusted for age, body mass index, emphysema lobe predominance, exercise capacity, and risk categorization. Adjusted $p$-values were calculated using the mixedeffects model for percentage difference of maximum inspiratory pressure, comparing between treatment groups by sex and visit time.

LVRS=lung volume reduction surgery; $\mathrm{CI}=$ confidence interval
}

BMI $\geq 25 \mathrm{~kg} / \mathrm{m}^{2}$ and thus, expected that the former would have only negligible increases in respiratory muscle strength after LVRS. However, we found that regardless of BMI, respiratory muscle strength increased at all follow-up periods. This confirms prior conclusions that inspiratory pressure also relies on the diaphragm contracting at an optimal length-tension curve, rather than solely on the inherent strength of the diaphragm muscle. ${ }^{10,12}$

A significant study limitation is that RMS measurements were obtained volitionally, making it difficult to interpret if MIP was truly low because of weakened respiratory muscles or falsely low because participants were not making maximal effort. Although the diaphragm is the dominant respiratory muscle, MIP is a global measurement of all inspiratory muscles. Therefore, from our results, we cannot imply that an increase in MIP is directly proportional to an increase in diaphragm strength, but rather may reflect an increase in external intercostal and accessory muscle strength. Additionally, although we found an association between a reduction in TLC, RV, FRC and RV/TLC and a corresponding increase in MIP at all follow-up periods, we cannot imply a direct and causal relationship that a reduction in hyperinflation led to an increase in inspiratory muscle strength.

An additional study limitation was that there was significant decrease in participants after 36 months, whether due to loss to follow-up or death. Therefore, despite having data at up to 5 years post-operatively, the lack of a large study size after 3 years makes it difficult to predict respiratory muscle strength beyond this time frame. As people continue to live longer, more adults will be living with emphysema at older ages. However, we were unable to analyze the effects of LVRS on respiratory muscle strength in those older 


\section{Table 6. Differences in Percentage Change of Maximum Inspiratory Pressure in Lung Volume Reduction Surgery Compared to Medical Arm at Each Time Point from Baseline for Emphysema Distribution and Exercise Capacity Age ${ }^{a}$}

\begin{tabular}{|c|c|c|c|c|c|}
\hline Visit (Months) & $\begin{array}{l}\text { LVRS } \\
\qquad(n)\end{array}$ & $\begin{array}{c}\text { Medical } \\
(n)\end{array}$ & $\begin{array}{l}\text { Difference } \pm \\
\text { Standard Error }\end{array}$ & $p$-value ${ }^{b}$ & $95 \% \mathrm{Cl}$ \\
\hline \multicolumn{6}{|l|}{6} \\
\hline Non-upper, Low Exercise & 63 & 43 & $+7.8 \pm 6.3$ & 0.2153 & $4.5-20.1$ \\
\hline Non-upper, High Exercise & 89 & 90 & $+17.9 \pm 4.9$ & 0.0002 & $8.4-27.5$ \\
\hline Upper lobe, Low Exercise & 121 & 97 & $+17.0 \pm 4.5$ & 0.0001 & $8.2-25.8$ \\
\hline Upper lobe, High Exercise & 175 & 169 & $+14.1 \pm 3.6$ & $<0.0001$ & $7.1-21.1$ \\
\hline High Risk & 41 & 39 & $+18.6 \pm 6.9$ & 0.0073 & $5.0-32.2$ \\
\hline \multicolumn{6}{|l|}{12} \\
\hline Non-upper, Low Exercise & 50 & 36 & $+7.2 \pm 7.2$ & 0.3168 & $-6.9-21.3$ \\
\hline Non-upper, High Exercise & 75 & 73 & $+11.2 \pm 5.5$ & 0.0426 & $0.4-22.1$ \\
\hline Upper lobe, Low Exercise & 105 & 69 & $+22.0 \pm 5.1$ & $<0.0001$ & $11.9-32.1$ \\
\hline Upper lobe, High Exercise & 153 & 150 & $+18.9 \pm 4.0$ & $<0.0001$ & $11.0-26.7$ \\
\hline High Risk & 37 & 34 & $+22.7 \pm 7.8$ & 0.0035 & $7.5-38.0$ \\
\hline \multicolumn{6}{|l|}{24} \\
\hline Non-upper, Low Exercise & 40 & 23 & $+17.5 \pm 8.3$ & 0.0350 & $1.2-33.8$ \\
\hline Non-upper, High Exercise & 67 & 66 & $+11.7 \pm 5.9$ & 0.0466 & $0.2-23.3$ \\
\hline Upper lobe, Low Exercise & 90 & 53 & $+13.8 \pm 5.9$ & 0.0191 & $2.2-25.3$ \\
\hline Upper lobe, High Exercise & 132 & 120 & $+12.3 \pm 4.3$ & 0.0043 & $3.8-20.7$ \\
\hline High Risk & 22 & 24 & $+4.9 \pm 9.4$ & 0.6041 & $-13.5-23.3$ \\
\hline \multicolumn{6}{|l|}{36} \\
\hline Non-upper, Low Exercise & 21 & 13 & $+18.9 \pm 10.0$ & 0.0582 & $-0.7-38.4$ \\
\hline Non-upper, High Exercise & 38 & 36 & $+13.3 \pm 6.8$ & 0.0498 & $0.01-26.7$ \\
\hline Upper lobe, Low Exercise & 59 & 23 & $+11.2 \pm 6.9$ & 0.1070 & $-2.4-24.7$ \\
\hline Upper lobe, High Exercise & 83 & 83 & $+9.6 \pm 4.6$ & 0.0384 & $0.5-18.7$ \\
\hline High Risk & 19 & 12 & $+1.4 \pm 10.7$ & 0.8937 & $-19.6-22.2$ \\
\hline
\end{tabular}

${ }^{\mathrm{a}} \mathrm{See}$ Table S5 in online data supplement for percentage differences in maximum inspiratory pressure from baseline to visit time for age.

${ }^{b} p$-value adjusted for age, body mass index, emphysema lobe predominance, exercise capacity, and risk categorization. Adjusted $p$-values were calculated using the mixed-effects model for percentage difference of maximum inspiratory pressure, comparing between treatment groups by sex and visit time.

LVRS=lung volume reduction surgery; $\mathrm{CI}=$ confidence interval; upper lobe=upper lobe predominant emphysema; non-upper=non-upper lobe predominant emphysema

than 70-years-old due to low sample size.

We report the effects of LVRS on inspiratory muscle strength in patients with advanced emphysema using data gathered from the largest and longest controlled trial to study this subject to date. Our analysis showed that LVRS significantly increases inspiratory muscle strength up to 3 years post-operatively, compared to optimal medical management for severely emphysematous patients. We found that an increase in inspiratory muscle strength was associated with a decrease in non-invasive markers of dynamic hyperinflation, suggesting that LVRS allows the inspiratory muscles to return to their optimal lengthtension relationship. Additionally, male sex, age
65- to 70-years-old and low exercise capacity with upper lobe predominant emphysema were associated with increased inspiratory muscle strength after LVRS.

The significant and durable increase in MIP following LVRS may be an additional physiological explanation for the increase in exercise tolerance and reduction in dyspnea compared to medical therapy alone. MIP is a simple, affordable and non-invasive pulmonary measurement and thus, could be used as an indirect marker for dynamic hyperinflation in post-LVRS patients.

\section{Acknowledgements}

Author contributions: Daohai Yu performed the data analysis. Rachel N. Criner and Gerard J. Criner interpreted the data. Rachel N. Criner drafted the manuscript. Rachel N. Criner, Gerard J. Criner, and Michael R. Jacobs revised the final draft. All authors approved the final version to be published.

The authors thank Matthew R. Maisel, BS, MS, for his assistance with data transformation. Clinical Trial: NCT00000606

\section{Declaration of Interest}

Dr. Gerard J. Criner received grants from the National Institutes of Health and the Department of Defense; he consults for AstraZenaca, Boehringer Ingelheim, Holaira, Mereo, Third Pole, PneumoRx, Pulmonx, Pearl, Amirall, CSA Medical, Broncus, AVISA, Lungpacer and GlaxoSmithKline. He has also contracted clinical trials from AstraZeneca, Avisa, Mereo, Boehringer Ingelheim, Broncus, GlaxoSmithKline, Lungpacer, Pulmonx, PneumoRx/BTG and Yungjin. All other authors have nothing to declare. 


\section{References}

1. Global Initiative for Chronic Obstructive Lung Disease (GOLD). Global Strategy for the Diagnosis, Management and Prevention of COPD, 2017. GOLD website doi: http://goldcopd.org Published 2017. Accessed July 2018.

2. Petrovic M, Reiter M, Zipko H, Pohl W, Wanke T. Effects of inspiratory muscle training on dynamic hyperinflation in patients with COPD. Int J COPD. 2012;7:797-805. doi: https://doi.org/10.2147/COPD.S23784

3. Rochester DF. Session 7: The respiratory muscles in COPD. Chest. 1984;85(6):47S-50S.

doi: http://dx.doi.org/10.1378/chest.8.6_Supplement.47S

4. Orozco-Levi M. Structure and function of the respiratory muscles in patients with COPD: impairment or adaptation? Eur Respir J. 2003;22(Suppl 46):41s-51s.

doi: https://doi.org/10.1183/09031936.03.00004607

5. Macklem PT, Macklem DM, De Troyer A. A model of inspiratory muscle mechanics. J Appl Physiol. 1983;55:547-557.

doi: https://doi.org/10.1152/jappl.1983.55.2.547

6. Rochester DF. The diaphragm in COPD: better than expected, but not good enough. N Engl J Med. 1991;325:961-962. doi: https://doi.org/10.1056/NEJM199109263251311

7. Laghi F, Tobin MJ. Disorders of the respiratory muscles. Am J Respir Crit Care Med. 2003;168(1):10-48.

doi: https://doi.org/10.1164/rccm.2206020

8. Cassart M, Pettiaux N, Gevenois PA, Paiva M, Estenne M. Effect of chronic hyperinflation on diaphragm length and surface area. Am J Respir Crit Care Med. 1997;156(2):504-508. doi: https://doi.org/10.1164/ajrccm.156.2.9612089

9. Ottenheijm CA, Heunks LM, Sieck GC, et al. Diaphragm dysfunction in chronic obstructive pulmonary disease. Am J Respir Crit Care Med. 2005;172(2):200-205. doi: https://doi.org/10.1164/rccm.200502-262OC

10. Testelmans D, Crul T, Maes K, et al. Atrophy and hypertrophy signaling in the diaphragm of patients with COPD. Eur Respir J. 2010;35:549-556.

doi: https://doi.org/10.1183/09031936.00091108

11. Criner G, Cordova FC, Leyenson V, et al. Effect of lung volume reduction surgery on diaphragm strength. Am J Respir Crit Care Med. 1998;157(5):1578-1585.

doi: https://doi.org/10.1164/ajrccm.157.5.9607081

12. Roussos C. Respiratory muscle fatigue and ventilatory failure. Chest. 1990;97(3):89S-95S.

doi: https://doi.org/10.1378/chest.97.3_Supplement.89S
13. Lando Y, Boiselle PM, Shade D, et al. Effect of lung volume reduction surgery on diaphragm length in severe chronic obstructive pulmonary disease. Am J Respir Crit Care Med. 1999;159(3):796-805.

doi: https://doi.org/10.1164/ajrccm.159.3.9804055

14. Martinez FJ, Montes de Oca M, Whyte RL, Stetz J, Gay SE, Celli BR. Lung-volume reduction improves dyspnea, dynamic hyperinflation, and respiratory muscle function. Am J Respir Crit Care Med. 1997;155(6):1984-1990.

doi: https://doi.org/10.1164/ajrccm.155.6.9196106

15. Sciurba FC, Rogers RM, Kennan RJ, et al. Improvement in pulmonary function and elastic recoil after lung-volume reduction surgery for diffuse emphysema. New Engl J Med. 1996;334:1095-1099.

doi: https://doi.org/10.1056/NEJM199604253341704

16. The National Emphysema Treatment Trial Research Group. Rationale and design of the National Emphysema Treatment Trial (NETT): a prospective randomized trial of lung volume reduction surgery. Chest. 1999;116(6):1750-1761. doi: https://doi.org/10.1378/chest.116.6.1750

17. National Emphysema Treatment Trial Research Group. A randomized trial comparing lung-volume-reduction surgery with medical therapy for severe emphysema. $N$ Engl J Med. 2003;348:2059-2073.

doi: https://doi.org/10.1056/NEJMoa030287

18. Black LF, Hyatt RE. Maximal respiratory pressures: normal values and relationship to age and sex. Am Rev Respir Dis.1969;99(5):696702. doi: https://doi.org/10.1164/arrd.1969.99.5.696

19. Teschler H, Stamatis G, El-Raouf Farhat AA, Meyer FJ, Costabel U, Konietzko N. Effect of surgical lung volume reduction on respiratory muscle function in pulmonary emphysema. Eur Respir J. 1996;9:1779-1784.

doi: https://doi.org/10.1183/09031936.96.09091779

20. Lammi MR, Marchetti N, Criner GJ. Reduced dynamic hyperinflation after LVRS is associated with improved exercise tolerance. Respir Med. 2014;108(10):1491-1497. doi: https://doi.org/10.1016/j.rmed.2014.07.015

21. Enright PL, Kronmal RA, Manolio TA, Schenker MB, Hyatt RB for the CHS Research Group. Respiratory muscle strength in the elderly: correlates and reference values. Am J Respir Crit Care Med. 1994;149(2):430-438.

doi: https://doi.org/10.1164/ajrccm.149.2.8306041

22. Harik-Khan R, Wise RA, Fozard JL. Determinants of maximal inspiratory pressure: the Baltimore Longitudinal Study of Aging. Am J Respir Crit Care Med. 1998;158(5):1459-1464. doi: https://doi.org/10.1164/ajrccm.158.5.9712006

23. Hautmann H, Hefele S, Schotten K, Huber RM. Maximal inspiratory mouth pressures (PIMAX) in healthy subjects-what is the lower limit of normal? Respir Med. 2000;94:689-693. doi: https://doi.org/10.1053/rmed.2000.0802 
24. Ingenito E, Loring SH, Moy ML, et al. Comparison of physiological and radiological screening for lung volume reduction surgery. Am J Respir Crit Care Med. 2001;163(5):10681073. doi: https://doi.org/10.1164/ajrccm.163.5.9911013

25. Kotloff RM, Hansen-Flaschen J, Lipson DA, et al. Apical perfusion fraction as a predictor of short-term functional outcome following bilateral lung volume reduction surgery. Chest. 2001;120(5):1609-1615.

doi: https://doi.org/10.1378/chest.120.5.1609

26. Celli BR, Cote CG, Marin JM, et al. The body-mass index, airflow obstruction, dyspnea, and exercise capacity index in chronic obstructive pulmonary disease. N Engl J Med. 2004;350:10051012. doi: https://doi.org/10.1056/NEJMoa021322 